\title{
Self-Perception Of Malocclusion And Barriers To Orthodontic Care: A Cross-Sectional Study In Al-Madinah, Saudi Arabia
}

This article was published in the following Dove Press journal: Patient Preference and Adherence

\author{
Rawah Talal Ashky' \\ Nebras Mohammed Althagafi' \\ Bayan Hussain Alsaati ${ }^{2}$ \\ Rayan Abdullah Alharbi ${ }^{2}$ \\ Saba Abdulla Kassim (iD) ${ }^{3}$ \\ Alla Talal Alsharif $\left(\mathbb{D}^{3}\right)^{3}$ \\ 'Department of Pediatric Dentistry and \\ Orthodontics, Taibah University Dental \\ College \& Hospital, Prince, Naif Ibn \\ Abdulazia, Al-Madinah Al-Munawwarah \\ 42353, Saudi Arabia; ${ }^{2}$ Taibah University \\ Dental College \& Hospital, Prince, Naif \\ Ibn Abdulazia, Al-Madinah \\ Al-Munawwarah 42353, Saudi Arabia; \\ ${ }^{3}$ Preventive Dental Sciences, Taibah \\ University Dental College \& Hospital, \\ Prince, Naif Ibn Abdulazia, Al-Madinah \\ Al-Munawwarah 42353, Saudi Arabia
}

Purpose: This study was conducted to assess adult levels of knowledge, awareness of malocclusion and barriers to the uptake of orthodontic care alongside the associated factors (sex and gender).

Methods: A convenience sample aged 18 years and above, residing in Al-Madinah AlMunawwarah, Saudi Arabia, was recruited. A self-administrated validated questionnaire was used to collect the data, and data descriptive and inferential statistical analysis were performed. Results: Of the 700 distributed questionnaires, 554 usable were returned (response rate = $79 \%$ ). The mean \pm SD age of participants was $26.40( \pm 7.87)$ years and $55.2 \%$ were females. Over $60 \%$ of the participants reported high oral health knowledge with respect to the alignment of teeth being important for esthetics and neglected malocclusion had consequences, eg, caries. Likewise, high percentages were having knowledge that thumb sucking $(80 \%)$ contributed to malocclusion although early extraction of primary teeth and genetics was reported by just $52 \%$ and $40 \%$, respectively. Awareness of the importance of teeth alignment was reported by $81.6 \%$; however, $37.7 \%$ were only advised for orthodontic treatment. Notably, most of the aforementioned knowledge and awareness was statistically significantly higher among females compared to counterpart males $(\mathrm{p}<0.05)$. As for barriers, high orthodontic treatment fees were the barrier for $80 \%$ of the total participants irrespective of age and gender. Females were statistically significantly more likely to report barriers for orthodontic care, eg, accessibility and length of treatment $(\mathrm{p}<0.05)$.

Conclusion: The majority of the participants scored high levels of knowledge and awareness of oral health-specific conditions in relation to malocclusion. Although females were significantly knowledgeable and aware of malocclusion compared to males, social and orthodontic treatment factors were perceived as barriers to uptake of orthodontic care.

Keywords: perception, orthodontic treatment, malocclusion, barriers
Correspondence: Nebras Mohammed Althagafi

Taibah University Dental College \&

Hospital, Prince, Naif Ibn Abdulazia,

Al-Madinah Al-Munawwarah 42353, Saudi

Arabia

Tel +966/4554434737

Email althagafi.nebras@gmail.com

\section{Introduction}

With a global dynamic process of self-awareness, there has been an increased concern about dental appearance, especially during adolescence and early adulthood. Currently, malocclusion has received more attention worldwide becoming the third in the rankings of dental public health priorities. ${ }^{1}$ Malocclusion is defined by Walther as an occlusion in which there is a mal-relationship between the arches in any of the planes or in which there are anomalies in the tooth's position, number, form, and developmental position of teeth beyond normal limits. ${ }^{2}$ The etiology of malocclusion is multifactorial, and several epidemiological studies have offered 
exploration tools that identify the various factors that might interfere with the position of the teeth and the normal pattern of skeletal growth. This includes oral habits (eg, thumb sucking), tooth anomalies, early primary teeth extraction and hereditary elements. ${ }^{3}$ In fact, clinical literature is replete with direct cause-effect relationships of occlusion problems with the two most prevalent oral health conditions, ie, dental caries ${ }^{4-6}$ and periodontal diseases. $^{5,7-9}$

However, malocclusion may also cause disturbances in oral functions such as mastication, swallowing and speech. ${ }^{10}$ Besides physical/functional outcomes, malocclusion has a substantial negative impact on patients' psychological/social measures (related to impaired dentofacial aesthetic) and quality of life (including self-esteem and self-image). ${ }^{11-14}$ Previous work has only focused on the professional WHO/FDI basic methods (ie, Dental Aesthetic Index ${ }^{15}$ and Index of Orthodontic Treatment Need) ${ }^{16}$ to record quantitative information about the prevalence and severity of malocclusion and to obtain estimates of the treatment needs of a population. ${ }^{15,17-19}$ The prevalence of malocclusion was varied in different populations from $39 \%$ to $93 \%$ making it clear that the majority of children have irregular teeth and malocclusion. ${ }^{20}$ Identical patterns of the prevalence of malocclusion were found among Saudi children and the young adult population. ${ }^{21-24}$ No data were recorded on the distribution of malocclusion among Saudi adult population.

The decision to pursue orthodontic treatment depends heavily on the subjective perceptions of patients' dental appearance, age, gender, peer-group norms and self-esteem. ${ }^{25}$ However, none of the self-perceived malocclusion assessment methods gained universal acceptance. The search of the literature revealed a paucity of published reports on the adult perception toward malocclusion and the potential barriers provided the rationale for the current investigation. In Saudi Arabia (SA), Essamet and Darout ${ }^{26}$ reported that over $65 \%$ of the study sample have a high knowledge towards orthodontic treatment needs; meanwhile, no discernible pattern or significant variation was found based on age or gender. ${ }^{26}$ Various dimensions of orthodontic treatment barriers were also addressed indicating that the financial costs and time-consuming nature of the treatment remain to have significant barriers to orthodontic care. $^{27}$

Our knowledge of Saudis' self-perception towards malocclusion and orthodontic treatment needs is largely based on very limited data. Understanding the perception-driven data will visualise the felt need and barriers to orthodontic care within the SA context. Such epidemiological studies may outline the need to design policies and generate practicebased evidence to address problems at multiple levels of the socio-ecologic model, from downstream (individual behavior interventions) to upstream (policy formulation).

The aim of this study was thus to: (1) describe the knowledge and awareness of malocclusion and orthodontic care needs within the context of Al-Madinah AlMunawwarah, SA, with a purpose of examining the role of sex/age differences and (2) investigate the potential barriers toward orthodontic treatment and their relevance across sex and age among adults in Al-Madinah Al-Munawwarah, SA. The null hypothesis was that gender and age have no role in explaining self-perception of malocclusion and barriers to orthodontic care.

\section{Materials And Methods Study Design, Setting And Participants' Recruitment}

This analytical cross-sectional study was conducted from March 2017 to May 2018 in Al-Madinah AlMunawwarah. This city is located in the Western region of the Kingdom of Saudi Arabia and consists of thirteen administrative regions. Al-Madinah Munawwarah has a total population of $1,183,205$; among this 655,470 $(53.7 \%)$ are male and the remaining 527,735 (46.3\%) are female. ${ }^{28}$ A convenience sample of 700 participants aged 18 years or older, Al-Madinah Al-Munawwarah residents were recruited. The recruitment of the study's participants was done via professional affiliations (researcher and associated colleagues). As this study has adopted a convenience sample of participant recruitment, the sample size was not calculated. However, based on the estimate of oral knowledge of malocclusion in Jazan, SA, reported by Essamet and Darout, ${ }^{26}$ the post hoc power calculation for this study was $100 \%$.

\section{Measurement And Data Collection}

Data were collected using an Arabic valid anonymous electronic self-administered questionnaire (Figure 1). ${ }^{29-31}$ This questionnaire which consisted of 20 questions and divided into four sections took about less than $10 \mathrm{mins}$ for the participants to complete. The four sections were as follows: Section one composed of demographic data of the participants (including age and gender). Section two consisted of 4 questions and investigating knowledge towards malocclusion and related oral diseases. In this section, participants were asked about the importance of teeth alignment for facial 
Questionnaire to assess the community self-perception toward malocclusion and the potential barrier to orthodontic care.

Part1: demographic data of the participant:

Age:

Gender: Male/ Female

Part 2: Questions related to the awareness towards the relationship between the malocclusion, dental caries and gingivitis.

A: Do you think malocclusion can cause dental caries?

Yes No I don't know

B: Do you think malocclusion can cause plaque accumulation?

Yes No I don't know

C: Do you think malocclusion can cause gingivitis?

Yes No I don't know

D: Do you think malocclusion can make dental brushing more difficult?

Yes No I don't know

Part 3: Questions related to knowledge and awareness toward orthodontic needs.

A: Are you aware about the important of aligned teeth?

Yes No I don't know

B: Do you think teeth must be well aligned?

Yes No I don't know

C: Do you think aligned teeth are important for facial appearance?

Yes No I don't know

D: Do you feel that you need orthodontic treatment?

Yes No I don't know

E: Did anyone advise you to align your teeth?

Yes No I don't know

F: Did you visit an orthodontist before?

Yes No I don't know

What do you think the reasons behind malocclusion

A: Thumb sucking can cause malocclusion to anterior teeth?

Yes No I don't know

B: Early extraction of primary teeth can cause malocclusion?

Yes No I don't know

C: Genetic can be the main reason for malocclusion?

Yes No I don't know

Part 4: Questions related to barriers to orthodontic care.

A: Cost and affordability?

Yes No I don't know

B: Multiple dental visits and transportation difficulty?

Yes No I don't know

C: Long term treatment?

Yes No I don't know

D: Unpleasant appearance?

Yes No I don't know

E: Require good oral hygiene maintenance?

Yes No I don't know

Figure I Questionnaire to assess the community self-perception toward malocclusion and the potential barrier to orthodontic care. 
esthetic, the consequences of malocclusion, eg, gingivitis, and finally, thumb sucking and early tooth extraction and genetics as predisposing agents to cause malocclusion. As for Section three which focused on awareness of malocclusion and seeking orthodontic care, participants' awareness of the importance of well-aligned teeth and perception to have braces to align their teeth or visited orthodontists for consultation were assessed. Finally, Section four focused on barriers to seek orthodontic care that relate to treatment (eg, pain, length of treatment) and socio-behavioral (eg, affordability of treatment, accessibility and oral hygiene). Accessibility barrier was adapted with Saudi community context. Responses for Section two, three and four questions were "Yes", "No" or "Do not know".

The questionnaire was created using HyperText Markup Language and sent using a direct link to a Google form to potential respondents (aforementioned as affiliated with researcher and associated colleagues) via software applications, ie, WhatsApp message. When the respondent had completed the questionnaire, they "submit" the web form back to the web server. The web server inserted the data into a database (Excel) created especially for the purpose of storing and retrieving the data for analysis.

\section{Ethical Approval}

The study was approved by ethical clearance obtained from Taibah University College of Dentistry Research Ethics Committee (TUCDREC/20170126/AlSaati) and conducted in accordance with the principles outlined by the World Medical Association in the Declaration of Helsinki. The questionnaire was preceded with a briefing about the study objectives and an e-mail of one of the researchers was made available for any inquires. Confidentiality was assured for any information provided since none of the personal identity information was requested (such as name or phone number) and all received data were collected automatically in one database sheet without differentiation. Consent forms were not obtained; however, the completion and the returning of the questionnaire was considered as an agreement to participate in the study.

\section{Statistical Analysis}

Data collected in an Excel sheet were imported for analysis into the Statistical Package for the Social Sciences (IBM SPSS Statistics for Mac, Version 21, Armonk, NY, USA). Descriptive analysis was carried out to report sample characteristics that included mean and standard deviation (SD) for continuous variables (eg, age) meanwhile as counts and percentages for categorical variables (eg, gender). Descriptive analyses for aspects of orthodontic awareness and knowledge alongside barrier were also performed. The responses for orthodontic knowledge and awareness alongside barriers were dichotomized into "Yes" or "No [No, Do not know]" to ease analysis and interpretation. Bivariate analyses including Chi-squared tests and Independent $T$-Test were used to examine the association of gender and age with the dependent variables of oral health knowledge and awareness items of malocclusion as well as for orthodontic care barriers. Results were considered significant at the $\mathrm{p}<0.05$.

\section{Results}

\section{Sample Characteristics}

Among the 700 distributed questionnaires, 554 usable were returned (response rate $=79 \%$ ). Of the respondents, $306(55.2 \%)$ were females and $248(44.8 \%)$ males with a mean/SD age $26.40 \pm 7.87$ years (range $18-77$ years).

\section{Description Of Knowledge And Awareness Of Malocclusion And Orthodontic Care}

Table 1 shows items related to knowledge and awareness of malocclusion. As for the importance of oral health knowledge of malocclusion in relationship with esthetics, high percentages (525 [94.8\%]) responded "Yes" that aligned teeth for facial esthetic was important. The knowledge of malocclusion to lead to oral diseases such as caries and gingivitis was reported by $405(73.1 \%)$ and 348 $(62.8 \%)$, respectively. With respect to the role of behavior in malocclusion, $443(80.0 \%)$ reported that thumb-sucking behavior could be the reason for malocclusion. However, approximately half of the respondents (288 [52.0\%]) had knowledge that early extraction of primary teeth can cause malocclusion in the future. As for oral health awareness items, a high number of respondents 452 (81.6\%) were aware of the importance of well-aligned teeth and 468 (84.5\%) thought that the teeth should be aligned properly. Approximately one-third of the participants (209 [37.7\%]) were only advised by their friends for orthodontic treatment, while $300(54.2 \%)$ visited an orthodontist for consultation.

\section{Potential Barriers Toward Orthodontic Treatment}

Figure 2 depicts the main barriers for respondents seeking orthodontic treatment. Affordability of the treatment 
Table I Description Of Respondents' Knowledge And Awareness Of Malocclusion And Orthodontic Care $(n=554)$, Al-Madinah, SA, $2017-2018$

\begin{tabular}{|c|c|c|c|c|c|}
\hline \multicolumn{2}{|l|}{ Oral Health Knowledge Variables } & n (\%) & \multicolumn{2}{|l|}{ Oral Health Awareness Variables } & n (\%) \\
\hline \multicolumn{3}{|l|}{ Esthetic } & \multicolumn{3}{|l|}{ Esthetic } \\
\hline \multirow{3}{*}{$\begin{array}{l}\text { Aligned teeth is important for facial } \\
\text { esthetic }\end{array}$} & Yes & $525(94.8)$ & \multirow[t]{3}{*}{ Importance of well aligned teeth } & Yes & $452(81.6)$ \\
\hline & No & $23(4.2)$ & & No & $78(14.1)$ \\
\hline & I don't know & $6(1.1)$ & & I don't know & $24(4.3)$ \\
\hline \multicolumn{6}{|l|}{ Malocclusion may lead to } \\
\hline \multirow[t]{3}{*}{ Dental caries } & Yes & $405(73.1)$ & \multirow{6}{*}{$\begin{array}{l}\text { Do you think that the teeth should be aligned } \\
\text { properly }\end{array}$} & Yes & $468(84.5)$ \\
\hline & No & $99(17.9)$ & & No & $61(11.0)$ \\
\hline & I don't know & $50(9.0)$ & & I don't know & $25(4.5)$ \\
\hline \multirow[t]{4}{*}{ Plaque accumulation } & Yes & $437(78.9)$ & & & \\
\hline & No & $59(10.6)$ & & & \\
\hline & I don't know & $58(10.5)$ & & & \\
\hline & & & \multicolumn{3}{|l|}{ Interest to orthodontic treatment variables } \\
\hline \multirow[t]{3}{*}{ Gingivitis } & Yes & $348(62.8)$ & \multirow[t]{6}{*}{ Felt need to put braces } & Yes & $348(62.8)$ \\
\hline & No & $116(20.9)$ & & No & $191(34.5)$ \\
\hline & I don't know & $90(16.2)$ & & I don't know & $15(2.7)$ \\
\hline \multirow[t]{3}{*}{ Difficulty in oral hygiene } & Yes & $493(89.0)$ & & & \\
\hline & No & $47(8.5)$ & & & \\
\hline & I don't know & $14(2.5)$ & & & \\
\hline \multicolumn{6}{|l|}{ Causes of malocclusion variables } \\
\hline \multirow[t]{3}{*}{ Thumb sucking } & Yes & $443(80.0)$ & \multirow[t]{6}{*}{ Advised by friends for orthodontics } & Yes & $209(37.7)$ \\
\hline & No & $61(11.0)$ & & No & $336(60.6)$ \\
\hline & I don't know & $50(9.0)$ & & I don't know & $9(1.6)$ \\
\hline \multirow[t]{3}{*}{ Early extraction of primary teeth } & Yes & $288(52.0)$ & & & \\
\hline & No & $|2|(2 \mid .8)$ & & & \\
\hline & I don't know & $145(26.2)$ & & & \\
\hline \multirow[t]{3}{*}{ Genetics } & Yes & $219(39.5)$ & \multirow[t]{3}{*}{ Visited orthodontist for consultation } & Yes & $300(54.2)$ \\
\hline & No & $164(39.5)$ & & No & $251(45.3)$ \\
\hline & I don't know & I7| (30.9) & & I don't know & $3(0.5)$ \\
\hline
\end{tabular}

was the main factor for $444(80 \%)$ out of 554, followed the bothersome appearance of braces represented by by $395(71 \%)$ of total respondents considering the dura- $251(45 \%)$ of responses as a potential barrier for tion of the treatment as an obstacle. On the other hand, treatment. 


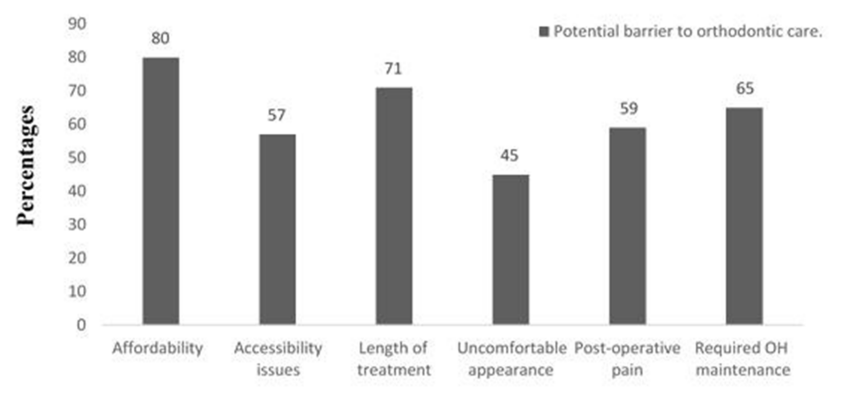

Figure 2 Potential barriers to orthodontic care $(n=554)$, Al-Madinah, SA, 2017-2018.

\section{Bivariate Analyses Of Oral Health Knowledge Of Malocclusion In Relationship To Gender And Age}

As shown in Table 2, females were statistically significantly more likely to be knowledgeable about the importance of aligned teeth for facial esthetics compared to males (229 [92.3\%] males vs 296 [96.7\%] females, $\mathrm{p}=0.034)$. As for the knowledge of consequences of malocclusion on oral health, specifically plaque accumulation, females were again statistically significantly more likely to be knowledgeable than their male counterparts (185 [74.6\%] males vs 252 [82.4\%] females, $p=0.034$ ) Table 2 . Notably, with respect to causes of malocclusion, males demonstrated statistical difference with respect to the role of early extraction of primary teeth in future malocclusion (143 [57.7\%] for males vs 145 [47.4\%] females, $p=0.020$ ), whereas females showed statistical differences in the knowledge about the role of thumb sucking in malocclusion (183 [73.8\%] males vs 260 [85.0\%] females, $\mathrm{p}=0.002$ ). However, both participating males and females did not differ with respect to other variables related to knowledge of malocclusion; $p>0.05$ (Table 2).
On the other hand, statistical significant differences (Table 2) were found in relation to mean age regarding the knowledge of gingivitis as consequences to malocclusion, where younger participants recorded higher knowledge levels than older ones $(25.9 \pm 7.4$ vs $27.3 \pm 8.5, p=0.043)$, while older participants were more knowledgeable regarding early extraction of primary teeth as cause of malocclusion (27.2 \pm 8.5 vs $25.6 \pm 7.1, \mathrm{p}=0.016$ ).

\section{Bivariate Analyses Of Oral Health Malocclusion Awareness In Relation To Gender And Age}

In oral health awareness bivariate analyses, most of the variables revealed statistically significant differences $(p<0.05)$ in relation to gender (Table 3 ). Females had significantly higher awareness levels than males regarding the importance of aligned teeth and thought teeth should be aligned properly (185 [74.6\%] males vs 267 [87.3\%] females, $\mathrm{p}=0.0001 ; 198$ [79.8\%] males vs 270 (88.2) females, $\mathrm{p}=0.009$, respectively). Also, females were more likely to have self-interest in orthodontic care since they reported statically significant differences in self-perception for orthodontic treatment and seeking orthodontists for consultation compared to males (137 [55.2\%] males vs $211[69.0 \%]$ females, $\mathrm{p}=0.001 ; 118[47.6 \%]$ males vs 182 [59.5\%] females, $p=0.007$, respectively).

On the other hand, statistically significant differences (Table 3) were found in relation to mean age. Younger participants were more likely to be aware than older participants regarding the following items: awareness of proper aligned teeth ( $26.1 \pm 7.6$ vs $28.0 \pm 9.0$ years old, $p=0.043$ ) and self-interest to get braces and visiting orthodontists for

Table 2 Bivariate Analyses Of Knowledge Of Malocclusion In Relationship To Gender And Age ( $n=554)$, Al-Madinah, SA, 20I7-20I8

\begin{tabular}{|c|c|c|c|c|c|}
\hline Oral Health Knowledge Variables & Male & Female & P-Value & Mean Age \pm SD & P-Value \\
\hline \multicolumn{6}{|l|}{ Esthetic } \\
\hline Aligned teeth is important for facial esthetic & $229(92.3)$ & $296(96.7)$ & 0.034 & $26.3 \pm 7.9$ vs $27.6 \pm 8.4$ & 0.463 \\
\hline \multicolumn{6}{|l|}{ Malocclusion may lead to } \\
\hline Dental caries & $177(7 \mid .4)$ & $228(74.5)$ & 0.407 & $26.5 \pm 8.0$ vs $26.1 \pm 7.6$ & 0.552 \\
\hline Plaque accumulation & $185(74.6)$ & $252(82.4)$ & 0.034 & $26.4 \pm 7.8$ vs $26.5 \pm 8.2$ & 0.896 \\
\hline Gingivitis & $151(60.9)$ & $197(64.4)$ & 0.449 & $25.9 \pm 7.4$ vs $27.3 \pm 8.5$ & 0.043 \\
\hline Difficulty in oral hygiene & $214(86.3)$ & $279(91.2)$ & 0.091 & $26.2 \pm 7.7$ vs $28.0 \pm 9.1$ & 0.086 \\
\hline \multicolumn{6}{|l|}{ Causes of malocclusion } \\
\hline Thumb sucking & $183(73.8)$ & $260(85.0)$ & 0.002 & $26.4 \pm 8.0$ vs $26.3 \pm 7.5$ & 0.928 \\
\hline Early extraction of primary teeth & I43 (57.7) & $145(47.4)$ & 0.020 & $27.2 \pm 8.5$ vs $25.6 \pm 7.1$ & 0.016 \\
\hline Genetics & $90(36.3)$ & $129(42.2)$ & 0.188 & $26.7 \pm 8.5$ vs $26.2 \pm 7.5$ & 0.454 \\
\hline
\end{tabular}

Note: Number in the table does not add up to total because of item negative responses were not reported. 
Table 3 Bivariate Analyses Of Participants' Awareness Of Malocclusion In Relationship To Gender And Age ( $n=554)$, Al-Madinah, SA, $2017-2018$

\begin{tabular}{|c|c|c|c|c|c|}
\hline Malocclusion Awareness Variables & Male & Female & P-Value & Mean Age \pm SD & P-Value \\
\hline \multicolumn{6}{|l|}{ Esthetic } \\
\hline Importance of well aligned teeth & $185(74.6)$ & $267(87.3)$ & 0.0001 & $26.2 \pm 7.8$ vs $27.2 \pm 8.2$ & 0.266 \\
\hline Do you think that the teeth should be aligned properly & $198(79.8)$ & $270(88.2)$ & 0.009 & $26.1 \pm 7.6$ vs $28.0 \pm 9.0$ & 0.042 \\
\hline \multicolumn{6}{|l|}{ Interest for orthodontic treatment } \\
\hline Felt need to put braces & $137(55.2)$ & $211(69.0)$ & 0.001 & $25.1 \pm 6.9$ vs $28.5 \pm 8.9$ & 0.0001 \\
\hline Advised by friends for ortho & $89(35.9)$ & $120(39.2)$ & 0.474 & $25.6 \pm 7.7$ vs $26.9 \pm 8.0$ & 0.073 \\
\hline Visited orthodontist for consultation & $118(47.6)$ & $182(59.5)$ & 0.007 & $25.6 \pm 6.8$ vs $27.4 \pm 8.9$ & 0.008 \\
\hline
\end{tabular}

Note: Number in the table does not add up to total because of item negative responses were not reported.

consultation $(25.1 \pm 6.9$ vs $28.5 \pm 8.9$ years old, $\mathrm{p}=0.0001$; $25.6 \pm 6.8$ vs $27.4 \pm 8.9$ years old, $\mathrm{p}=0.008$, respectively).

\section{Bivariate Analyses Of Potential Barriers For Orthodontic Care In Relationship To Gender And Age}

Table 4 demonstrates that females were statistically significantly more likely to report barriers for orthodontic care that included accessibility (125 [50.4\%] males vs 190 [62.1\%] females, $p=0.007)$, length of treatment (162 [65.3\%] males vs 233 [76.1\%] females, $\mathrm{p}=0.007)$ and post-operative pain (128 [51.6\%] males vs 200 [65.4\%] female, $\mathrm{p}=0.001)$. However, no gender differences were found $(\mathrm{p}>0.05)$ in relation to other barriers (eg, affordability). In addition, age had no significant relationship $(p>0.05)$ with orthodontic care barriers (Table 4).

\section{Discussion}

The aims of this study were to describe the knowledge and awareness of malocclusion and orthodontic care needs within the context of Al-Madinah Al-Munawwarah, SA, with a purpose of testing for sex/age differences, and to investigate the potential barriers toward orthodontic treatment and their relevance across sex and age among adults in Al-Madinah Al-Munawwarah, SA.

As reported elsewhere, ${ }^{26,32}$ the self-awareness in this study showed that most of the respondents agreed on the importance of the well-aligned teeth for facial esthetic. Over half of the participants in this study have visited an orthodontist or were advised to consult an orthodontic specialist. The participants were aware of the wellknown relevance of malocclusion with dental caries, periodontal conditions and other fields of medicine (eg, chronic diseases). Moreover, the majority of the participants were oriented of the cascading effects of thumbsucking behavior and early primary teeth extraction on the overall oral health dysfunction, including malocclusion. Our findings appear to be well supported by previous literature. ${ }^{3,26}$

In this study, the null hypothesis of no gender differences in males' and females' awareness, knowledge has been rejected. Within the context of SA, these findings refute previous results reported by Essamet and Darout ${ }^{26}$ from Jizan, SA, who stated that "there is no statistical difference found between males and females in awareness, knowledge and behavior related to orthodontic treatment need". 26

Table 4 Chi-Square And T-Tests Of Barriers To Orthodontic Care In Relationship To Gender And Age ( $\mathrm{n}=554)$, Al-Madinah, SA, 2017-2018

\begin{tabular}{|l|l|l|l|l|l|}
\hline Potential Barrier To Orthodontic Treatment Variables & Male & Female & P-Value & Mean Age \pm SD & P-Value \\
\hline Affordability & $190(76.6)$ & $254(83.0)$ & 0.077 & $26.1 \pm 7.7$ vs $27.6 \pm 8.6$ & 0.086 \\
Accessibility issues & $125(50.4)$ & $190(62.1)$ & 0.007 & $26.9 \pm 8.2$ vs $25.7 \pm 7.4$ & 0.087 \\
Length of treatment & $162(65.3)$ & $233(76.1)$ & 0.007 & $26.7 \pm 8.0$ vs $25.7 \pm 7.5$ & 0.202 \\
Uncomfortable appearance & $108(43.5)$ & $143(46.7)$ & 0.508 & $26.9 \pm 8.2$ vs $26.0 \pm 7.6$ & 0.141 \\
Post-operative pain & $128(51.6)$ & $200(65.4)$ & $0.00 I$ & $25.9 \pm 7.8$ vs $27.1 \pm 8.0$ & 0.085 \\
Required OH maintenance & $168(67.7)$ & $194(63.4)$ & 0.328 & $26.4 \pm 8.0$ vs $26.4 \pm 8.0$ & 0.957 \\
\hline
\end{tabular}

Note: Number in the table does not add up to total because of item negative responses were not reported.

Abbreviation: $\mathrm{OH}$, oral health. 
The explanatory models of sex roles need to be acknowledged to fully explain the influence of socio-cultural values on seeking orthodontic treatment and identify barriers to seeking care. Although clinical data suggested that orthodontic needs may be greater among males, ${ }^{21,22,33}$ evidence of increased self-interest in orthodontic care and facial appearance among females in this study compared with males are congruent with previous studies. ${ }^{32,34,35}$ This was also reflected in the number of female participants who visited an orthodontic clinic for consultation.

As for the second part of our hypothesis that there were no age differences in explaining self-perception of malocclusion and barriers to orthodontic care, this study suggested that younger participants have shown higher knowledge of malocclusion and its relationship with oral health problems (eg, gingivitis) than the older subgroup. However, our findings in contrast to Kim's study ${ }^{30}$ which showed respondents in their $40 \mathrm{~s}$ and $50 \mathrm{~s}$ showed considerably high interest towards orthodontic treatment. It is well documented that the nature and complexity of malocclusion increases in middle-aged and older adult patients. Thus, the more invasive and serious a treatment is, the greater the costs involved that can create financial strain. Therefore, generational differences in orthodontic care-seeking behavior may raise different priorities on health-care planning and policy formulation, so addressing this public health issue is extremely important.

It becomes clear that the barriers in receiving adequate orthodontic care is not a single explanation, but a combination of factors. Geographic locations of health services and affordability issues have always created inequality in health outcomes all over SA, namely for females. ${ }^{36}$ However, no noteworthy significant differences were found between gender when it comes to affordability barrier. Our findings aligned with a study in Asser, ${ }^{27}$ who found that most of the participants perceived high treatment costs, accessibility and long treatment time as barriers to orthodontic care. Looking at the health-care system in SA, the public sector (only major hospitals) provides free orthodontic care for individuals in our community. However, patients with malocclusion and those who are in need for orthodontic treatment would wait up to 5 years to be seen by an orthodontic at a public hospital. Alternatively, the private sector dominates in the world of dentistry, providing all levels of dental care from emergency to specialized care, including orthodontics. With a higher proportion of private dental clinics and over $78 \%$ of orthodontics operating in private clinics, ${ }^{37}$ it is not surprising that the main option for Saudis to seek orthodontic care is from private practices. The cost of orthodontic treatment in private practices is based on market forces, with an average cost of $\$ 5000-\$ 10,000$ per individual. ${ }^{38}$ Unfortunately, young adults are most likely to avoid treatment, due to high costs.

It is plausible that several limitations could have influenced the results obtained. The convenient sample technique used does not represent the whole population. Many young cohorts of participants were involved; hence generalizability of the results should be done with caution. Also, it would have been better if this study had explored the respondents' socio-economic status that may have played a role in their perception. In fact, the complexity of measuring the socioeconomic status in SA and to avoid bothering the participants, the questionnaire should be structured to be short and quickly answered to encourage completion. The cross-sectional design of the study precluded the causality, the nature of data collection (texts) and the self-election to participate in the study may have biased the results.

The strengths of our study included the high response rate and the use of validated questionnaires. This study has gone some way towards enhancing our understanding of the felt orthodontic care need, and in fact, it highlights the need to focus our resources and develop strategies and services regarding such public health issues. Further studies, which take a more representative sample into account, will need to be undertaken. Further rigorous clinical orthodontic needs assessment research with a particular insight into different socioeconomic determinants is also required.

\section{Conclusion}

The majority of the participants scored high level of knowledge and awareness of oral health-specific conditions in relation to malocclusion. Females were found significantly knowledgeable and aware of orthodontic care compared to males. Gender difference in seeking orthodontic care was linked to certain aspects of orthodontic treatment and social barriers. Economic factors as well as the length of treatment act as barriers in receiving orthodontic care in a Saudi context.

\section{Disclosure}

The authors report no conflicts of interest in this work.

\section{References}

1. Dias PF, Gleiser R. O índice de necessidade de tratamento ortodôntico como um método de avaliação em saúde pública. Rev Dent Press Ortod E Ortop Facial. 2008;13(1). doi:10.1590/s1415-54192008000 100009

2. Houston W, Walther D. Walther's Orthodontic Notes. 4th ed. The Stonebridge Publishers; 2000. 
3. Grippaudo C, Paolantonio EG, Antonini G, Saulle R, La Torre G, Deli R. Association between oral habits, mouth breathing and malocclusion associazione. Acta Otorhinolaryngol Ital. 2016;36(5):386394.

4. Borzabadi-Farahani A, Eslamipour F, Asgari I. Association between orthodontic treatment need and caries experience. Acta Odontol Scand. 2011;69(1):2-11. doi:10.3109/00016357.2010.516732

5. Nalcaci R, Demirer S, Ozturk F, Altan BA, Sokucu O, Bostanci V. The relationship of orthodontic treatment need with periodontal status, dental caries, and sociodemographic factors. Sci World J. 2012;2012:498012 doi:10.1100/2012/498012

6. Sá-Pinto AC, Rego TM, Marques LS, Martins CC, Ramos-Jorge ML, Ramos-Jorge J. Association between malocclusion and dental caries in adolescents: a systematic review and meta-analysis. Eur Arch Paediatr Dent. 2018;19:73-82. doi:10.1007/s40368-018-0333-0

7. Buckley LA. The relationships between irregular teeth, plaque, calculus and gingival disease. A study of 300 subjects. Br Dent J. 1980;148:67-69. doi:10.1038/sj.bdj.4804378

8. Gábris K, Márton S, Madléna M. Prevalence of malocclusions in Hungarian adolescents. Eur J Orthod. 2006;28(5):467-470. doi:10. 1093/ejo/cj1027

9. Bollen A-M. Effects of malocclusions and orthodontics on periodontal health: evidence from a systematic review. J Dent Educ. 2008;72(8):912-918.

10. Proffit WR, Fields HW. Contemporary Orthodontics. Mo, USA: Mosby, St. Louis; 2007.

11. Choi SH, Kim JS, Cha JY, Hwang CJ. Effect of malocclusion severity on oral health-related quality of life and food intake ability in a Korean population. Am J Orthod Dentofac Orthop. 2016;149 (3):384-390 doi:10.1016/j.ajodo.2015.08.019

12. Dimberg L, Arnrup K, Bondemark L. The impact of malocclusion on the quality of life among children and adolescents: a systematic review of quantitative studies. Eur J Orthod. 2015;37:238-247. doi:10.1093/ejo/cju046

13. Kenealy P, Frude N, Shaw W. An evaluation of the psychological and social effects of malocclusion: some implications for dental policy making. Soc Sci Med. 1989;28(6):583-591. doi:10.1016/0277-9536 (89)90253-0

14. Helm S, Kreiborg S, Solow B. Psychosocial implications of malocclusion: a 15-year follow-up study in 30-year-old Danes. Am J Orthod. 1985;87:110-118. doi:10.1016/0002-9416(85)90020-X

15. Brook PH, Shaw WC. The development of an index of orthodontic treatment priority. Eur J Orthod. 1989;11(3):309-320. doi:10.1093/ oxfordjournals.ejo.a035999

16. Cons NC, Jenny J, Kohout FJ, Songpaisan Y, Jotikastira D. Utility of the dental aesthetic index in industrialized and developing countries. $J$ Public Health Dent. 1989;49(3):163-166 doi:10.1111/j.17527325.1989.tb02054.x

17. Summers CJ. The occlusal index: a system for identifying and scoring occlusal disorders. Am J Orthod. 1971;59(6):552-567. doi:10.1016/0002-9416(71)90002-9

18. Salzmann JA. Handicapping malocclusion assessment to establish treatment priority. Am J Orthod. 1968;54(10):749-765. doi:10.1016/ 0002-9416(68)90065-1

19. Draker HL. Handicapping labio-lingual deviations: a proposed index for public health purposes. Am J Orthod. 1960;46(4):295-305. doi:10.1016/0002-9416(60)90197-4

20. Thilander B, Pena L, Infante C, Parada SS, De Mayorga C. Prevalence of malocclusion and orthodontic treatment need in children and adolescents in Bogota, Colombia. Eur J Orthod. 2001;23 (2):153-167. doi:10.1093/ejo/23.2.153
21. Al-Hummayani FM, Taibah SM. Orthodontic treatment needs in Saudi young adults and manpower requirements. Saudi Med J. 2018;39(8): 822-828. doi:10.15537/smj.2018.8.22337

22. Gudipaneni RK, Aldahmeshi RF, Patil SR, Alam MK. The prevalence of malocclusion and the need for orthodontic treatment among adolescents in the northern border region of Saudi Arabia: an epidemiological study. BMC Oral Health. 2018. doi:10.1186/s12903-018-0476-8

23. Al-Emran S, Wisth PJ, Böe OE. Prevalence of malocclusion and need for orthodontic treatment in Saudi Arabia. Community Dent Oral Epidemiol. 1990;18(5):253-255 doi:10.1111/j.1600-0528.1990.tb00070.x

24. Al-Jobair AM, Baidas LF, Al-Hamid AA, Al-Qahtani SG, Al-Najjar AT, Al-Kawari HM. Orthodontic treatment need among young Saudis attending public versus private dental practices in Riyadh. Clin Cosmet Investig Dent. 2016;8:121-129.

25. Mandall NA, Wright J, Conboy F, Kay E, Harvey L, O’Brien KD. Index of orthodontic treatment need as a predictor of orthodontic treatment uptake. Am J Orthod Dentofac Orthop. 2005;128:703-707. doi:10.1016/j.ajodo.2004.10.011

26. Essamet M, Darout IA. Awareness and behavior related to orthodontic treatment among Jazan University students, Kingdom of Saudi Arabia. J Dent Oral Hyg. 2016. doi:10.5897/jdoh2015.0184

27. Almoammar S, Asiri E, Althogbi S, et al. Knowledge and attitude of general population towards orthodontic treatment in Aseer region, Kingdom of Saudi Arabia. World J Dent. 2018;8(6):483-489 doi:10.5005/jp-journals-10015-1491

28. General Authority for Statistics in Kingdom of Saudi Arabia. The general population and housing census; 2018. Available from: https:// www.stats.gov.sa/ar/13. Accessed October 27, 2018.

29. AlQarni MA, Banihuwaiz AH, Alshehri FD, Alqarni AS, Alasmari DS. Evaluate the malocclusion in subjects reporting for orthodontic treatment among Saudi population in Asser region. J Int Oral Heal. 2014;6(4):42-46.

30. Kim Y. Study on the perception of orthodontic treatment according to age: a questionnaire survey. Korean J Orthod. 2017;47(4):215-221. doi:10.4041/kjod.2017.47.4.215

31. Muqtadir Quadri S, Thilagrani P, Dhanyasi AK, Mongia J, Agrawal A. Awareness towards orthodontic treatment in central Indian school children. Sch J Dent Sci. 2015;2(1):45-48.

32. Li X, Tang Y, Huang X, Wan H, Chen Y. Factors influencing subjective orthodontic treatment need and culture-related differences among Chinese natives and foreign inhabitants. Int J Oral Sci. 2010;2:149-157. doi:10.4248/ijos 10050

33. Jones WB. Malocclusion and facial types in a group of Saudi Arabian patients referred for orthodontic treatment: a preliminary study. $\mathrm{Br} J$ Orthod. 2014;14(3):143-146. doi:10.1179/bjo.14.3.143

34. Tayer BH, Burek MJ. A survey of adults' attitudes toward orthodontic therapy. Am J Orthod. 1981;79:305-315. doi:10.1016/0002-9416 (81)90078-6

35. Tulloch JFC, Shaw WC, Underhill C, Smith A, Jones G, Jones M. A comparison of attitudes toward orthodontic treatment in British and American communities. Am J Orthod. 1984. doi:10.1016/0002-9416 (84)90064-2

36. World Health Organization. Health Systems Profile-Saudi Arabia. 2006. Available from: http://apps.who.int/medicinedocs/documents/ s17308e/s17308e.pdf. Accessed September 18, 2019.

37. AlBaker AA, Al-Ruthia YSH, AlShehri M, Alshuwairikh S. The characteristics and distribution of dentist workforce in Saudi Arabia: a descriptive cross-sectional study. Saudi Pharm J. 2017;25:1208-1216. doi:10.1016/j.jsps.2017.09.005

38. ValuePenguin. The average cost of braces. 2019. Available from: https:// www.valuepenguin.com/average-cost-braces. Accessed May 31, 2019. 


\section{Publish your work in this journal}

Patient Preference and Adherence is an international, peer-reviewed, open access journal that focusing on the growing importance of patient preference and adherence throughout the therapeutic continuum. Patient satisfaction, acceptability, quality of life, compliance, persistence and their role in developing new therapeutic modalities and compounds to optimize clinical outcomes for existing disease

states are major areas of interest for the journal. This journal has been accepted for indexing on PubMed Central. The manuscript management system is completely online and includes a very quick and fair peer-review system, which is all easy to use. Visit http:// www.dovepress.com/testimonials.php to read real quotes from published authors. 